\title{
Genetic variants linked to T2DM risk in Kurdish populations
}

\author{
Shadi Golsheh' \\ Fatemeh Keshavarzi ${ }^{2}$ \\ 'Department of Biology, Kurdistan \\ Science and Research Branch, Islamic \\ Azad University, Sanandaj, Iran; \\ ${ }^{2}$ Department of Biology, Sanandaj Branch, \\ Islamic Azad University, Sanandaj, Iran
}

This article was published in the following Dove Press journal:

Diabetes, Metabolic Syndrome and Obesity: Targets and Therapy

Background: The polymorphisms of the $\mathrm{C}-\mathrm{C}$ chemokine ceptor type insulin receptor substrate I (IRSI) have been studied cand in for the usceptibility to develop type 2 diabetes mellitus (T2DM). CCR5 is a chokine recep an nolymorphisms in the promoter region of this receptor are bein. udied a andidates w the susceptibility to develop T2DM. Also, IRSI is a critical factor i he slo pathway insulin, and mutations in this gene have been reported, which con ute to the a to to the T2DM. The aim of the current study was to determine re onship beth CCR5 (59029A/G) and IRSI (rs 10498210) polymorphisms with T2DM in Sa, dajian patients.

Methods: Genomic DNA w solaced from 200 lthy individuals and 220 Kurdish T2DM patients by salt extraction nethod and the polymorphisms were examined by restriction fragment length polymorph $n(R F L P) m e$ od and then the results were analyzed using Chisquare test.

Results: The fi qu of $A A$ cype in 220 Kurdish patients for both genes CCR5 $(O R=1.9, P=0.02$, and $I F \quad P R[95 \% C l]=2.62, P=0.02)$ were significantly more than controls There was rgnificant association between AG or GG genotypes in with T2DM. Cor asion The pr ence of AA homozygote alleles in both loci of IRSI (rs I04982 10) and $5(5902,-/ G)$ gen increased the risk of T2DM.

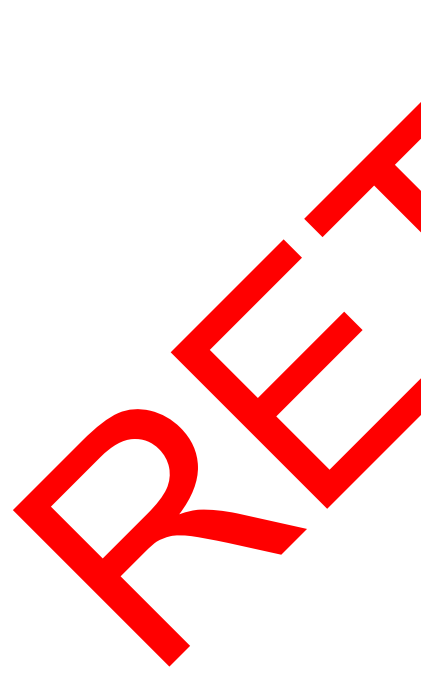

Ke, or :TRST (10498210), CCR5 (59029A/G), type 2 diabetes, Kurdish patients

\section{troduction}

Dian tes or diabetes mellitus is referred to as a heterogeneous group of metabolic disorders characterized by chronic hyperglycemia and carbohydrate, fat and protein metabolism disorders that result from a defect in the secretion of insulin, or impairment in its function, or both. Types of diabetes mellitus include type 1 , type 2 diabetes and other kind of diabetes, but the two most common types of diabetes mellitus are type 1 and type 2 , which are different in several aspects. ${ }^{1,2}$ Type 1 diabetes has been identified with autoimmune destruction of pancreatic beta cells (insulin secreting cells) and accounts for about 5\% of all diabetic people, while type 2 diabetes mellitus (T2DM) is a predominant disorder characterized by insulin resistance or a relative decline in insulin production, and accounts for about $90 \%$ of all types of diabetes mellitus. ${ }^{3}$ Important factors that predispose a person to T2DM are multifactorial, including genetic factors and environments. However, its inheritance has certainly not been proven, but it is believed that first-degree relatives of diabetic patients have a higher chance to develop the disease. In this regard, recognizing gen polymorphisms of this disease seems to be necessary. ${ }^{4}$

Correspondence: Fatemeh Keshavarz Sanandaj Branch, Islamic Azad University, Pasdaran Avenue, Sanandaj, Iran

Tel +989183704918

Fax +988733288677

Email fkeshavarzi@iausdj.ac.ir 
Multiple genes have been studied in the pathogenesis of T2DM. One of these genes associated with T2DM is the IRSI gene (accession number. 147545). ${ }^{5-8}$ Another gene associated with T2DM is the CCR 5 gene (accession number. 601373). ${ }^{9-11}$

Insulin initiates a wide range of growth and metabolic effects by binding to its receptor and activating the property of tyrosine kinase. These events cause phosphorylation of tyrosine kinase residues at the level of anchored proteins, which include insulin receptor substrate proteins (IRS). ${ }^{12}$ The phosphorylated IRS proteins are used as multi-position anchored proteins for different molecules that have homologous domains (SH2) or Src. The activity of these second SH proteins triggers the signaling cascade and results in the activity of several downstream filters that ultimately transmits the insulin message to the cellular vector pathways, thereby regulating cell differentiation, growth, survival and metabolism. In different studies, the frequency of IRS1 polymorphisms in type 2 diabetic patients was more than control group. ${ }^{13-15}$ The IRS1 is a cytoplasmic substrate for insulin and also is a receptor for $I G F-1$, which plays a vital role in signaling. In recent studies, various roles in IRS1 have been discovered, especially in patients with non-insulin diabetes mellitus. The IRSI gene polymorphisms were identified $1993 .{ }^{16,17}$

Chemokines are a large family of low molec secretion proteins that play fundamental roles ir and pathophysiological processes such inflammation, atherosclerosis and auto mune argic or infectious diseases. ${ }^{18,19}$ Their initial ction is to the late the migration of leukocytes at the cor entrat gradient, but they also play a role in the actiy of of the cen producing and secreting inflammatory n alators. These chemonines do their function by connectí to cir G-protein receptors. ${ }^{19}$ Excessive nutrition and ha leve of glucose and fatty acids can pu oress the atic islets and insulinsensitive ti es such and and liver and muscle, leading to the production elease of topical cytokines and inflammatory chemokines. mong these inflammatory chemokines, MCP-1, MIP-1 $\alpha$, $M I P-1 \beta, \quad R A N T E S$ (Regulated upon Activation, Normal T-cell Expressed, and Secreted) and $M C P-2$ are mentioned. These chemokines interact with their receptors, triggering monocytes, as well as increasing the number of macrophages in the inflammation position. Chemokine receptors that can be mentioned include CCR2 (CC chemokine receptor type 2), chemokine receptor MCP-1, and also chemokine receptors CCR5, MIP-1 $\alpha, M I P-1 \beta$, RANTES and $M C P-2 .^{21}$
The CCR5 gene is located at $3 \mathrm{q} 21.3$ position on the chromosome. The CCR5 (59029A/G) polymorphism has been reported in the promoter region of the CCR 5 receptor gene. ${ }^{22}$ Studies indicated that the CCR5 (59029A/-) genotype results in increased expression of this receptor by peripheral blood mononuclear cells of individuals with this genotype, and therefore it is probably the genotype regulating the expression of the CCR 5 gene. ${ }^{9,20}$

In this regard, the relationship between the IRSI (rs10498210) polymorphisms and CCR5 (59029A/G) and the risk of T2DM have not been clearly precisely indicated. Therefore, this study was co acted $m$ the aim of investigating this relationship.

\section{Methods}

\section{Ethical statem}

The study was nically ap ved the regional Ethics Committee sas daj Branch slamic Azad University, and the study was con cted in accordance with the provisions the Declaration Helsinki.

Sai ples

This ro rch i case-control study. During this study, the Pheral blood samples of $220 \mathrm{~T} 2 \mathrm{DM}$ patients (fasting od g. cose higher than $150 \mathrm{mg} / \mathrm{dL}$ in two times) and non-200 diabetic subjects as control (fasting blood glucose ss than $100 \mathrm{mg} / \mathrm{dL}$ in two times and gender- and ethnicmatched with the patients). Patients were selected randomly among individuals who referred to the Kurdistan Diabetes Centers in Kurdistan of Iran. Patients were selected in such a way that their diabetes was controlled (measured by HbAlc by the diabetes center). Inclusion criteria were diagnosed according to the American Diabetes Association diagnostic criteria (the blood glucose level of $>250 \mathrm{mg} / \mathrm{dL}$ or severe hyperglycemia). Written consent was received from the individuals and they were informed that sampling was for research purposes only.

\section{DNA extraction}

Extraction of DNA from the blood samples was performed by salt extraction method and DNA extraction was determined on agarose gel $1 \%$. The isolated DNA was placed in separate microtubes and stored at $-20^{\circ} \mathrm{C}$ until PCR was performed.

\section{Molecular analysis}

Determination of genotype was carried out by PCR-RFLP method and the primers (Table 1) were used for replication 
Table I The sequences of primers used in the study for IRSI (rs I04982I0) and CCR5 (59029A/G)

\begin{tabular}{|c|c|c|}
\hline & IRSI (rs| $04982 \mid 0)$ & CCR5 (59029A/G) \\
\hline Forward & 5'-ACAGCCAAAAGGTAAAGCGT-3' & 5'-CCCGTGAGCCCATAGTTAAAACTC-3' \\
\hline Reverse & 5'-CCCTTCTCAAAGTACAGCATGT-3' & 5'-TCACAGGGCTTTTCAACAGTAAGG-3' \\
\hline Product size & bp37I & bp258 \\
\hline
\end{tabular}

Abbreviation: T2DM, type 2 diabetes mellitus.

of pieces. For the CCR5 $(59029 \mathrm{~A} / \mathrm{G})$ polymorphism, the primers were taken from other articles but for IRSI (rs10498210) polymorphism was designed.

PCR was performed in final volume of $20 \mu \mathrm{l}$ using Sinagene PCR kit. The PCR cycles of the desired gene are presented in Table 2 separately. To ensure the correct replication of the desired piece, the PCR products were loaded on agarose gel $1.8 \%$. and its quality was determined.

In order to cut the desired region in the CCR5 gene, the SduI enzyme was selected, which is detected as GGGCAC, and consequently, in the presence of the allele G in polymorphic position, enzyme cut the piece and in the presence of the allele $\mathrm{A}$, the piece does not cut. The piece produced by PCR for the CCR 5 gene is a 258 bp base pair piece, and if the piece is cut, two pieces of 131 and 127 bases are created. To cut the desired region in the IRSI gene, the MaeII enzy selected, which is detected as ACGT. The PCR-prolif gted piece is $371 \mathrm{bp}$. In the presence of the allele $G$ in the $\mathrm{p}$ morphic position, the enzyme has cut posit n, wh h resu in two pieces of 229 and $142 \mathrm{bp}$, and the pres ace of th allele $\mathrm{A}$ at the polymorphic positio the 1, piece is not broken, and totally one piece w emain. Th the digested products were loaded on 3\% garo vel and the senotypes were determined. Achiey frequencic ignificance between type 2 and control sy ects were statistica $y$ analyzed using software popgene 2 and SPSS v20 and at significant level $(p<0.05)$

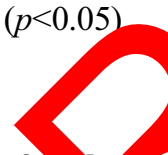

Table 2 o oliferation Conditions

\begin{tabular}{|c|c|c|c|c|c|}
\hline Genes & Initial denaturation & Denaturation & Annealing & Extension & Final extension \\
\hline \multicolumn{6}{|c|}{ Cycling condition } \\
\hline \multirow[t]{2}{*}{ CCR5 } & $94^{\circ} \mathrm{C}$ & $94^{\circ} \mathrm{C}$ & $60^{\circ} \mathrm{C}$ & $72^{\circ} \mathrm{C}$ & ${ }^{\circ} 72^{\circ} \mathrm{C}$ \\
\hline & $4 \operatorname{Min}$ & $30 \mathrm{Sec}$ & $60 \mathrm{Sec}$ & $60 \mathrm{Sec}$ & $5 \mathrm{~min}$ \\
\hline \multicolumn{6}{|c|}{ Repeated for 34 Cycles } \\
\hline \multirow[t]{2}{*}{ IRSI } & $94^{\circ} \mathrm{C}$ & $94^{\circ} \mathrm{C}$ & $60^{\circ} \mathrm{C}$ & $72^{\circ} \mathrm{C}$ & $72^{\circ} \mathrm{C}$ \\
\hline & 4 Min & $30 \mathrm{Sec}$ & $60 \mathrm{Sec}$ & $60 \mathrm{Sec}$ & $5 \mathrm{~min}$ \\
\hline
\end{tabular}

\section{Results}

This case-control study was performed on 420 unrelated individuals, including 220 patients with type 2 diabetic and 200 healthy controls. The allele quench genotypes for all two SNPs were shown Table 3. In he population studied, the frequency $\$$, AG $\mathrm{nG}$ g otypes of the CCR5 gene were 12 (54.54), 84 8.1, and 16 (7.27), respectively, amon the pat its and 8 (40.5), 70 (35) and 49 (24.5), res ctively the con subjects. Also, in the IRS1 gene vas as foll s: nong the 220 patients, the frequen of A AG and OG was 150 (68.18), 52 (23.63) and 20 (9.09), resp ively, and also, among the 200 control rojects, the frequency of GG, AG and AA were 176 (88), 20 $10)$ and 4 ( 2 respectively. In patients, the allelic frequency AA in bot genes CCR5 (OR $(95 \% \mathrm{CI})=1.9 P=0.02)$ and $I R S$. $5 \% \mathrm{CI})=2.62 \quad P=0.02$ ) were significantly more n controls. There was no significant association between AG or GG genotypes in with T2DM (Table 3).

Figure 1 shows the image of the agarose gel $3 \%$ for $C C R 5$ (59029A/G) polymorphism and also shows how to determine its genotype in ladder and size pieces as described above.

Figure 2 shows the image of the agarose gel 3\% for IRS1 (rs10498210) polymorphism and also shows how to determine its genotype in ladder and size pieces as described in "Molecular analysis" section.

In this study, Hardy Weinberg equilibrium and heterozygosity were also studied for populations. The Hardy Weinberg 
Table 3 Distribution of alleles and genotypes of CCR5 (59029A/G) and IRSI (rsI04982I0) genes among T2DM patients and healthy controls

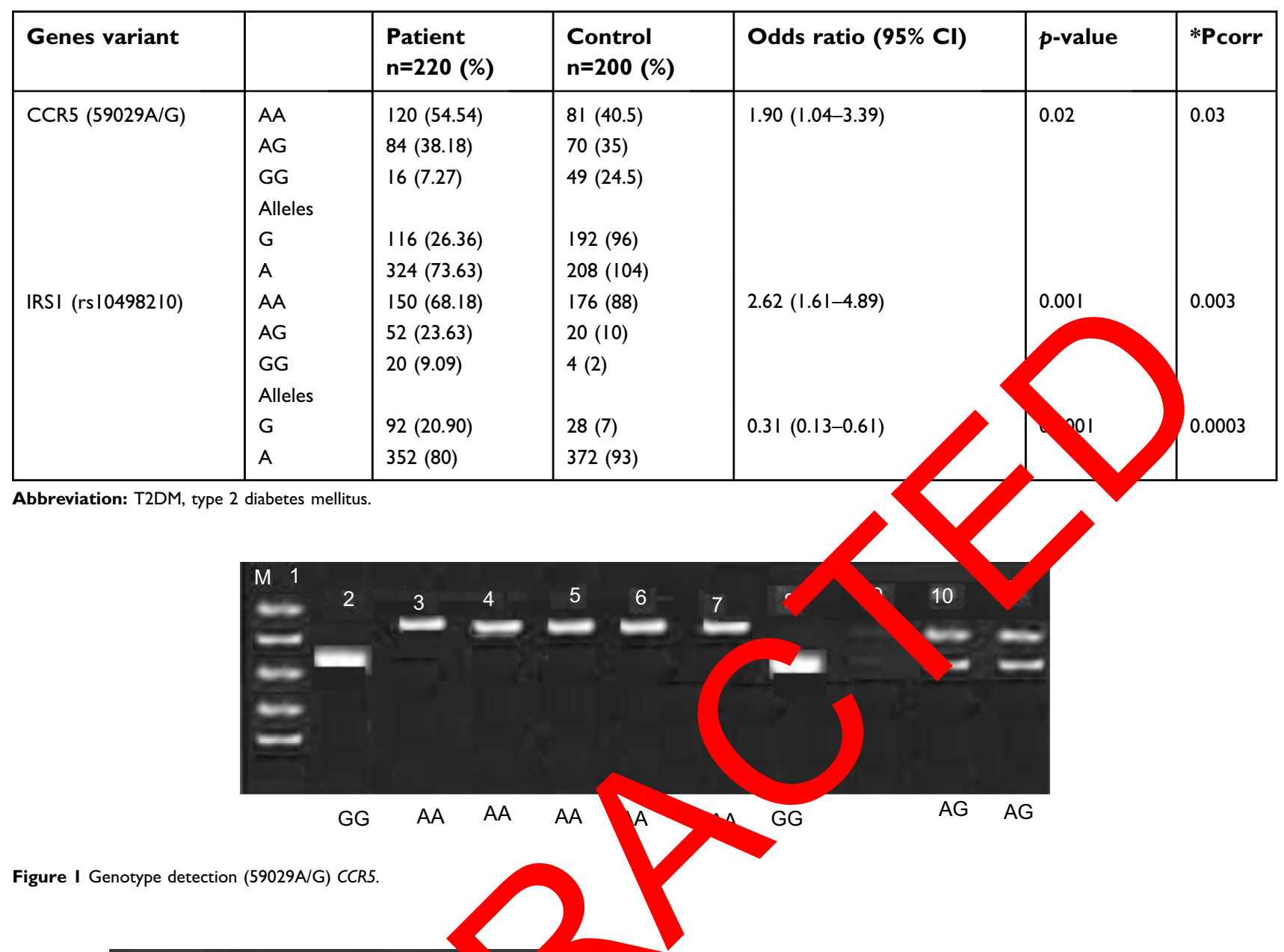

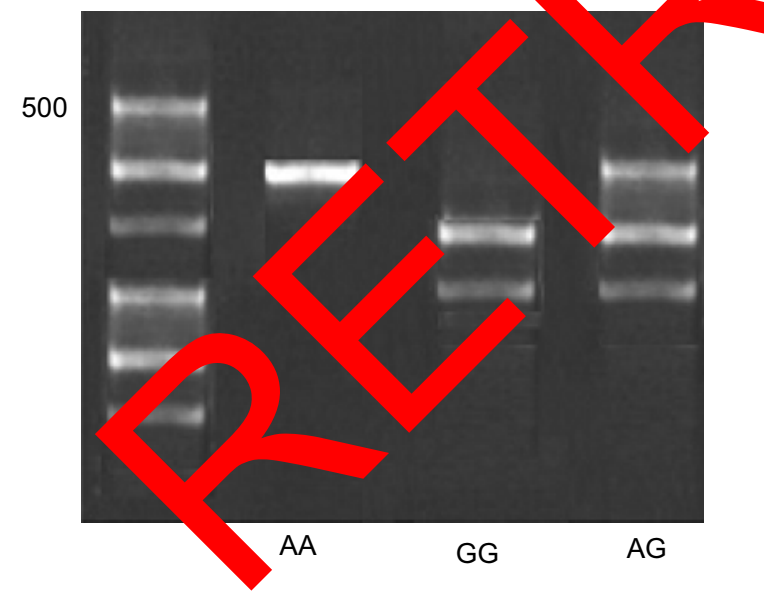

Figure 2 Genotype detection (rsI04982I0) IRSI.

equilibrium points to the fact that the genetic and genotype frequency is constant from generation to generation. The probability level in both type 2 diabetic and control subjects was greater than 0.05 for IRS1 and CCR5 genes, indicating a Hardy Weinberg equilibrium in these populations (Table 3).
Heterozygosity for a gene position is defined as a frequency of heterozygote people for that position relative to the total population. For a gene position, if the heterozygosity is greater than 0.1 , it is polymorphic and if it is more than 0.7 , it is extremely polymorphic. Based on the results of this study, it was found that the difference between observed and expected heterozygosity for both studied polymorphisms was less than 0.1 , so that the gene positions in this study are not polymorphic. In the next step, the mean of patient's clinical data which were collected from their files in Diabetes Center of Kurdistan was analyzed. The results of clinical data analysis are presented in Tables 4 and 5 .

\section{Discussion}

This case-control study was performed on patients and healthy control from Iranian Kurdistan. The frequencies of genotypes and alleles for all two SNPs are shown in Table 3. Results show that among patients and control subjects the 
Table 4 Comparison of type 2 diabetic patients' clinical data among different genotypes of polymorphism IRSI (rs I04982I0)

\begin{tabular}{|l|l|l|l|}
\hline Clinical data & AG-GG & AA-GG & AA-AG \\
\hline Weight & 0.196 & 0.107 & 0.536 \\
Systolic blood pressure & 0.995 & 0.633 & 0.700 \\
Diastolic blood pressure & 0.154 & 0.027 & 0.203 \\
Total cholesterol & 0.322 & 0.057 & 0.447 \\
Triglyceride & 0.532 & 0.443 & 0.958 \\
Cholesterol HDL & 0.428 & 0.000 & 0.000 \\
Cholesterol LDL & 0.277 & 0.098 & 0.288 \\
Fasting blood glucose & 0.924 & 0.029 & 0.016 \\
HBAIC & 0.428 & 0.453 & 0.768 \\
\hline
\end{tabular}

Table 5 Comparison of type 2 diabetic patients' clinical data among different genotypes of polymorphism CCR5 (59029A/G)

\begin{tabular}{|l|l|l|l|}
\hline Clinical data & AG-GG & AA-GG & AA-AG \\
\hline Weight & 0.664 & 0.075 & 0.156 \\
Systolic blood pressure & 0.000 & 0.211 & 0.086 \\
Diastolic blood pressure & 0.540 & 0.867 & 0.079 \\
Total cholesterol & 0.263 & 0.000 & 0.000 \\
Triglyceride & 0.061 & 0.771 & 0.219 \\
Cholesterol HDL & 0.102 & 0.077 & 0.536 \\
Cholesterol LDL & 0.430 & 0.000 & 0.000 \\
Fasting blood glucose & 0.000 & 0.000 & 0.220 \\
HBAIC & 0.798 & 0.456 & 0.4 \\
\hline
\end{tabular}

allelic frequency AA, AG and GG genot , of te $C C$ gene were 120 (54.54), 84 (38.18) as $16(7 / 2$ and 8 (40.5), 70 (35) and 49 (24.5), resp Avely. o, in the IRS1 gene it was as follows: amono 220 patio the allelic frequency of $\mathrm{AG}, \mathrm{AG}$ and $G$ was 50 (68.18), 52 (23.63) and 20 (9.09), respectiy, and also, a ng the 200 control subjects, the freque of GC AG and $\lambda$ A was 176 (88), 20 (10) and 4 ( $\mathrm{resp}$ ively. The frequency of AA genotype in wents ooth ge CCR5 (OR (95\% CI) $=1.9 P=0 \quad 2$ ) an IRSI $\quad 5 \% \mathrm{CI})=2.62 \quad P=0.02$ ) was signifi tly $\mathrm{mo}$ thon controls. There was no significant association ween $A G$ or GG genotypes with T2DM (Table 3). A weight, systolic blood pressure, diastolic blood pressure, otal cholesterol, triglyceride, cholesterol HDL, cholesterol LDL, fasting blood glucose and HBA1C were significantly higher in the patients' group when compared to the control group (Tables 4 and 5).

McDermott et al., who found for the first time the A/G polymorphism in the 59029 base pair in the promoter region of this gene, reported that both alleles of this polymorphism are common in societies, and the allelic frequency of 59029A, depending on the ethnic population, varies between $43 \%$ and $68 \%$. Differences in the frequency of allelic A in different communities can be due to genetic differences between populations. ${ }^{22,23}$

According to the results, it is possible that the CCR5 genotype (AA 59029) plays an important role in the pathogenesis of T2DM. Studies indicated that the CCR5 $(59029 \mathrm{~A} /-)$ genotype results in increased expression of CCR 5 by peripheral blood mononuclear cells of individuals with this genotype. In a study by Dytfeld et al., the expression of CCR 5 receptor expression was measured on the peripheral blood mononuclear cells of type iabetics, and it was determined that the expression $C C R 5 \mathrm{n}$ ptor on the cell surface in type 2 diabetic patio is also incr sing, and high expression of this recept can bo nnsidere as an indicator of atherosclerosis in abetic poople.

Given the exia of $\angle \mathrm{DM}$ which was recently provided and ty 2 dia $s$ introd ed as an inflammatory disease, $j$ be expec. at high expression of this receptor $C C R$, n the level of single-cellular cells of the bl creases in nmatory responses and increases the $\mathrm{sk}$ of T2DM. However, in order to confirm with certainty he existenc of such a connection, further studies in a vider pop ation are needed.

Mn the role of IRSI gene in the pathway of lin signaling and the negative effect of rs 10498210 polymorphism on the performance of this protein, it can be expected that this polymorphism is present in the etiology of T2DM. Recent studies have indicated that IRSI plays an important role in regulating insulin secretion in beta cells of the pancreas. It has been shown that glucosestimulated insulin secretion may be triggered by the autocrine activation of insulin signaling pathway, including insulin receptor phosphorylation, tyrosine phosphorylation in IRSI and the activation of PI3-Kinase.

Putting together these data leads to the hypothesis that a single molecular impairment in the pathway of insulin signaling, including an incomplete interaction between PI3-Kinase and IRS1, may lead to insulin resistance, as well as insulin secretion defect.

So far, there has been a weak link between this polymorphism and T2DM, especially in obese people, but few studies have reported the association between this polymorphism and diabetes. In general, a variety of allele A in IRS1 frequencies have been reported in many studies, and controversial reports have revealed the association of this polymorphism with type 2 diabetes. ${ }^{25}$ Finally, according to the results of this study, it can be concluded that the probability of positive effect of allele A on studied 
polymorphisms IRSI (rs10498210) and CCR5 (59029A/G) increase the risk of T2DM. Also, clinical data from diabetic patients suggest that the allele A from both studied polymorphisms plays a positive role in increasing the risk of cardiovascular disease in type 2 diabetic patients. However, to be sure about the impact of these polymorphisms on T2DM, it is necessary to study a larger population. It is also possible to compare the clinical data of patients with healthy subjects and examine the effect of these two polymorphisms on the clinical data of these two groups and more effectively to study the role of these polymorphisms in increasing the risk of disease cardiovascular disease. The two studied genes in current study are associated with insulin resistance based on two different mechanisms. IRSI plays a role in the insulin signaling pathway in its target tissues and CCR5 plays a role in the inflammation pathway in fatty tissues and beta cells in the pancreas. By simultaneous examination of these two genes and the effect of their different variants together, in type 2 diabetic patients, greater recognition of the importance of each of these pathways in the pathogenesis of T2DM can be obtained.

\section{Conclusion}

The presence of AA homozygote alleles in both loci of IRS , (rs10498210) and CCR5 (59029A/G) genes incre ar risk of T2DM. There was no significant association etween $G$ or GG genotypes in with T2DM.

\section{Acknowledgment}

The authors would like to nk the volt. eers who contributed samples for this cudy.

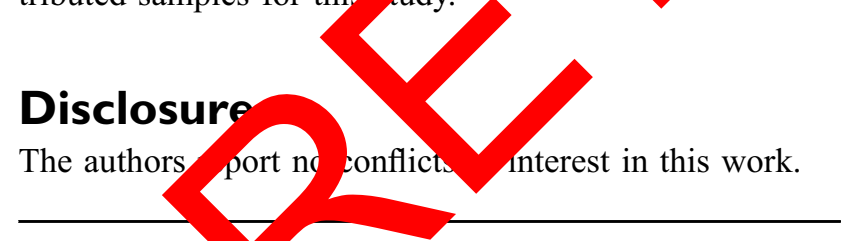

\section{Reference}

1. Bhattacharya S, Dey Roy SS. Molecular mechanism of insulin resistance. J Biosci. 2007;32(2):405-413.

2. Meshkani R, Taghikhani M, Mosapour A, et al. 1484insG polymorphism of the PTPN1 gene is associated with insulin resistance in an Iranian population. Arch Med Res. 2007;38(5):556-562. doi:10.1016/j. arcmed.2007.01.010

3. Meshkani R, Taghikhani M, Al-Kateb H, et al. Polymorphisms within the protein tyrosine phosphatase 1B (PTPN1) gene promoter: functional characterization and association with type 2 diabetes and related metabolic traits. Clin Chem. 2007;53(9):1585-1592. doi:10.1373/ clinchem.2007.088146
4. Häring HU, Merker L, Seewaldt-Becker E, et al. Empagliflozin as add-on to metformin in patients with type 2 diabetes: a 24-week, randomized, double-blind, placebo-controlled trial. Diabetes Care. 2014;37(6):1650-1659. doi:10.2337/dc13-2105

5. Brunetti A, Chiefari E, Foti D. Recent advances in the molecular genetics of type 2 diabetes mellitus. World J Diabetes. 2014;5 (2):128-140. doi:10.4239/wjd.v5.i2.128

6. Brender JR, Krishnamoorthy J, Messina GM, et al. Zinc stabilization of prefibrillar oligomers of human islet amyloid polypeptide. Chem Commun (Camb). 2013;49:3339-3341. doi:10.1039/c3cc40383a

7. Alharbi KK, Khan IA, Munshi A, Alharbi FK, Al-Sheikh Y, Alnbaheen MS. Association of the genetic variants of insulin receptor substrate 1 (IRS1) with type 2 diabetes mellitus in a Saudi population. Endocrine. 2014;47(2):472-477. doi:10.1007/s12020-014-0177-2

8. Alharbi KK, Khan IA, Abotalib Z, Al-Hake M. Insulin receptor substrate-1 (IRS1) Gly927Arg: correlat with g tional diabetes mellitus in Saudi women. Biomed es Int. 2014, 14:146-495. doi:10.1155/2014/146495

9. Mokubo A, Tanaka Y, Nakai a K, d. Chemot ic cytokine receptor 5 (CCR5) gene moter polym hism, 9029A/G) is associated with diabetic ohropath Japan atients with type 2 diabetes: a 10-year lo tudin study. Diabetes Res Clin Pract. 2006;73(1):89-94 A:10. \ drabres.20 2.006

10. Balistreri CR, uso C, Gru di MP al. Ccr5 receptor. Ann N Y Acad Sc A 100(1):162- Oi:10.1196/annals.1395.014

11. Muntinghe $L$, Gro S, Bakker S, et al. CCR5 $\triangle 32$ genotype is associated with outcon in type 2 diabetes mellitus. Diabetes Res Cli raw 2009;86(2):14 45. doi:10.1016/j.diabres.2009.08.013

12. Ite MF. The insulin signalling system and the IRS proteins. abetologia. 19 :40(2):S2-S17.

13. I i HZ, Makmo Bakry M, Hashim R, Mustafa N, Wan Ngah WZ. Op isation of ycaemic control during episodes of severe/acute hypers in patients with type 2 diabetes mellitus. Int J Clin 2012;34(6):863-870. doi:10.1007/s11096-012-9682-7

14 A, Exercise HM. GLUT4, and skeletal muscle glucose uptake. Physiol Rev. 2013;93:993-1017. doi:10.1152/physrev.00038.2012

15. Chang YJ, Pownall S, Jensen TE, et al. The Rho-guanine nucleotide exchange factor PDZ-RhoGEF governs susceptibility to diet-induced obesity and type 2 diabetes. eLife. 2015;4:e66011. doi:10.7554/ eLife. 06416

16. Audouze K, Brunak S, Grandjean P. A computational approach to chemical etiologies of diabetes. Sci Rep. 2013;3:2712. doi:10.1038/srep02712

17. Ullrich S. IGF-1 and Insulin-Receptor Signalling in Insulin-Secreting Cells: From Function to Survival. Islets of Langerhans. Islets of langerhans: Springer; 2015:659-685.

18. Herder C, Haastert B, Müller-Scholze S, et al. Association of systemic chemokine concentrations with impaired glucose tolerance and type 2 diabetes: results from the Cooperative Health Research in the Region of Augsburg Survey S4 (KORA S4). Diabetes. 2005;54(suppl 2):S11-S17.

19. Baggiolini M. Chemokines in pathology and medicine. J Intern Med. 2001;250(2):91-104.

20. Ahluwalia TS, Khullar M, Ahuja $\backslash$ M, et al. Common variants of inflammatory cytokine genes are associated with risk of nephropathy in type 2 diabetes among Asian Indians. PLoS One. 2009;4(4):e5168. doi:10.1371/journal.pone.0005168

21. Abbas A, Lichtman A, Pillai S. Cellular and Molecular Immunology: With Student Consult Online Access. Islets of langerhans: Elsevier Health Sciences; 2014.

22. McDermott DH, Zimmerman PA, Guignard F, et al. CCR5 promoter polymorphism and HIV-1 disease progression. Lancet. 1998;352 (9131):866-870. doi:10.1016/S0140-6736(98)04158-0

23. Passam AM, Zafiropoulos A, Miyakis S, et al. CCR2-64I and CXCL12 3' A alleles confer a favorable prognosis to AIDS patients undergoing HAART therapy. J Clin Virol. 2005;34(4):302-309. doi:10.1016/j.jcv.2004.05.021 
24. Dytfeld J, Bogdański P, Pupek-Musialik D, Jagodziński P, Bryl W, Kujawa A. Expression of chemokine receptor CCR5 in patients with type 2 diabetes. olskie Towarzystwo Lekarskie. 2006;20 (116):195-198.
25. Yousef AA, Eg B, Abd Allah W, et al. IRS1 genetic polymorphism (r.2963G $>$ A) in type 2 diabetes mellitus patients associated with insulin resistance. Appl Clin Genet. 2018;11:99-106.

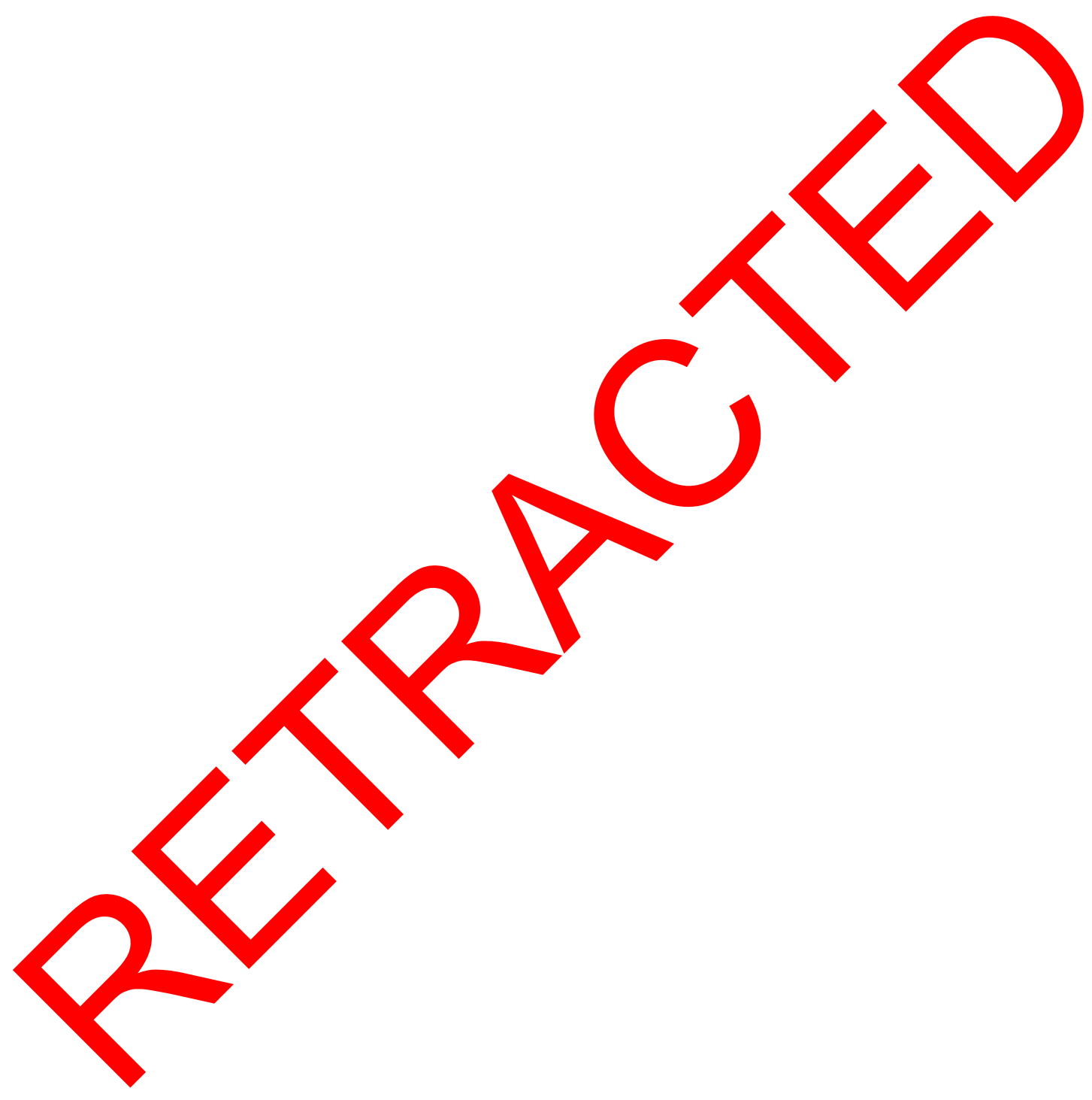

Diabetes, Metabolic Syndrome and Obesity: Targets and Therapy

\section{Publish your work in this journal}

Diabetes, Metabolic Syndrome and Obesity: Targets and Therapy is an international, peer-reviewed open-access journal committed to the rapid publication of the latest laboratory and clinical findings in the fields of diabetes, metabolic syndrome and obesity research. Origina research, review, case reports, hypothesis formation, expert opinion and commentaries are all considered for publication. The manuscript management system is completely online and includes a very quick and fair peer-review system, which is all easy to use. Visit http://www.dovepress.com/testimonials.php to read real quotes from published authors. 